\title{
The Significance of Positive Electrization on Lifting Force
}

\section{Yuri Pivovarenko}

Research and Training Centre 'Physical and Chemical Materials Science' Under Kyiv Taras Shevchenko University and NAS of Ukraine, Kiev, Ukraine

\section{Email address: \\ y.pivovarenko@gmail.com}

\section{To cite this article:}

Yuri Pivovarenko. The Significance of Positive Electrization on Lifting Force. American Journal of Aerospace Engineering. Vol. 4, No. 6, 2017, pp. 59-62. doi: 10.11648/j.ajae.20170406.11

Received: December 28, 2017; Accepted: January 16, 2018; Published: February 7, 2018

\begin{abstract}
Due to the daily rotation of the Earth the lower layers of earth's atmosphere are continuously crossed by horizontal lines of the geomagnetic field. For this reason, near the earth's surface there is an upward-directed Lorentz force. Under the action of this force the positively charged objects move upward and the negative charges down. As a result, this force can increase the lift of flying objects that have a positive charge: water vapor, birds, insects, airplanes and space rockets. In addition, the action of the upward directed Lorentz force blocks the deflection of the racket's body in the horizontal direction, that is, ensures its equilibrium.
\end{abstract}

Keywords: Evaporation, Insects, Flying Insects, Birds, Flying Birds, Rockets

\section{Introduction}

There is data showing that near the earth's surface there is a force under which the positive charges move upward and the negative charges down [1]. It was shown earlier [2, 3] that described force is the Lorenz force that appears due to the daily rotation of the Earth relative to the geomagnetic field (Figure 1).

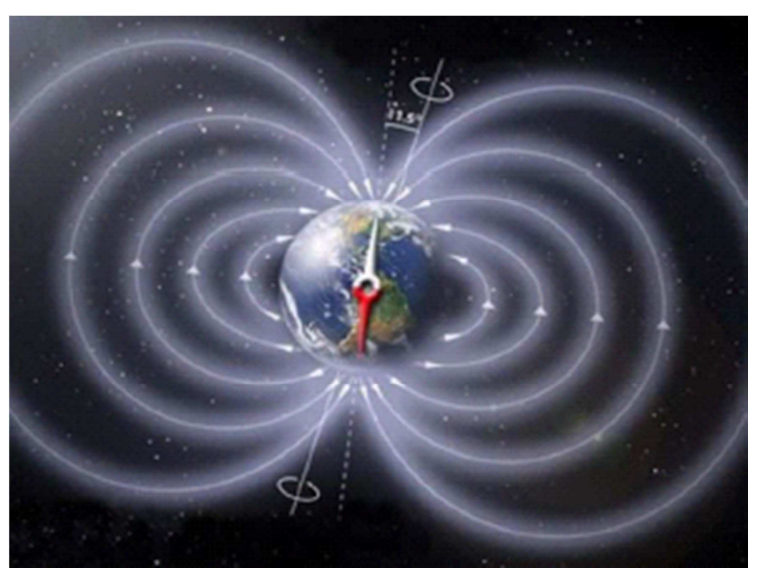

Figure 1. This is planet Earth and the lines of force of the geomagnetic field. As the Earth has daily rotation all objects on its surface cross the horizontal lines of force of the geomagnetic field. The appeared Lorenz force distributes the charges located on the earth's surface. Wherein the positively charged particles move up and negatively charged - down.
This can also be seen (Figure 1), the objects on the Earth's surface or in earth's atmosphere cross the horizontal lines of the geomagnetic field during such movement.

Obviously, in such conditions on the Earth's surface and in the near-earth atmosphere appears as a Lorentz force $F_{L}$, directed upwards (1):

$$
\mathrm{F}_{\mathrm{L}}=\mathrm{q} \cdot[\mathrm{v}, \mathrm{B}],
$$

where: $q$ - electric charge,

$\mathrm{v}$ - the linear speed of earth's surface,

$\mathrm{B}$ - geomagnetic induction [4].

The presence of this force explains the positive charge of the upper atmosphere and negative charge to the earth's surface, and the polarization of the clouds: it is known that the lower part of a typical cloud has a negative charge and upper - positive charge (Figure 2) [1].

It should also be said that the mentioned Lorentz force $F_{L}$ causes the formation of jets of steam (Figure 3, left) and smoke (Figure 3, right) [2, 3, 5]. Thus, jets of steam and smoke represent the flow of positive charges, i.e. electric currents in the classic sense, namely, the currents associated with the transfer agent or currents move, according to Maxwell.

It is obvious that the described lifting action of the Lorentz force $\mathrm{F}_{\mathrm{L}}$ only applies to positively charged objects. However, the positive electrification of such objects is not always 
obvious. For this reason, analyses cause positive electrification of some objects that tend to rise up.

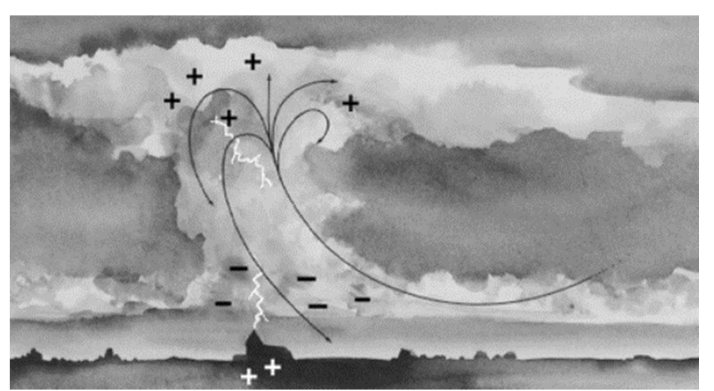

Figure 2. This is a typical cloud and its polarization: the lower part of a typical cloud has a negative charge and the upper part has a positive charge.
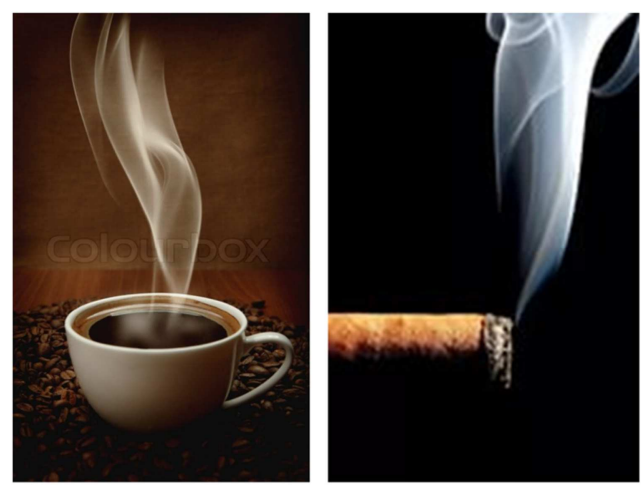

Figure 3. It has jets of steam rising over a cup of coffee (left) and cigar smoke (right). It is clear that the particle density of steam and smoke is greater than the density of the air.

\section{Results}

\section{Boiling water and hot steam}

It is known that hot steam has a positive charge $[2,5]$. To explain this phenomenon, it is necessary to use the rule of

$$
1,602 \cdot 10^{-19} \mathrm{~A} \cdot \mathrm{s} \leftrightarrow 2,55 \cdot 10^{-21} \mathrm{Kg} \mathrm{H}_{2} \mathrm{O} \text { or: } 1,602 \cdot 10^{-19} \mathrm{C} \leftrightarrow 2,55 \cdot 10^{-18} \mathrm{~g} \mathrm{H}_{2} \mathrm{O} .
$$

Transform this proportion:

$$
\begin{gathered}
1,602 \cdot 10^{-19} \mathrm{C} / 2,55 \cdot 10^{-18} \leftrightarrow \\
\leftrightarrow 2,55 \cdot 10^{-18} / 2,55 \cdot 10^{-18} \mathrm{~g} \\
\text { or: } 6,28 \cdot 10^{-2} \mathrm{C} \leftrightarrow 1 \mathrm{~g} \mathrm{H}_{2} \mathrm{O} .
\end{gathered}
$$

Thus, in the earth's conditions $1 \mathrm{~g}$ of water steam can carry a charge, of $+6,28 \cdot 10^{-2} \mathrm{C}$ [2]. Apparently, this is an unusually
Kyon: upon contact of the two phases, the phase which has high dielectric permittivity receives a positive charge [6]. Since the dielectric permittivity of hot water vapor is $\sim 1$ [7], and dielectric permittivity of boiling water is 55,1 [6], boiling water should acquire a positive charge during contact with the vapor bubbles, which are constantly formed in the process of boiling water. Thus, the positive electrization of boiling water is in accordance with the described rule. As a result, the boiling water is constantly allocating small positively charged associates of hot water, namely water vapor, which rises under the action described by the Lorentz force $\mathrm{F}_{\mathrm{L}}(1)$.

To determine the mass of water $\mathrm{m}_{\mathrm{w}}$, which "can be raised" with a single proton, can form an equation:

$$
\left|\mathrm{F}_{\mathrm{L}}\right|^{*}=\mathrm{m}_{\mathrm{w}} \cdot|\mathrm{g}|,
$$

where: $\left|\mathrm{F}_{\mathrm{L}}\right|^{*}\left(=2,5 \cdot 10^{-20} \mathrm{Kg} \cdot \mathrm{m} \cdot \mathrm{s}^{-2}\right)-$ the described Lorenz force acting on proton at the equator, $|\mathrm{g}|\left(=9,81 \mathrm{~m} \cdot \mathrm{s}^{-2}\right)-$ the gravity acceleration at the equator.

From this equation it was found:

$$
\begin{aligned}
\mathrm{m}_{\mathrm{w}}=\left|\mathrm{F}_{\mathrm{L}}\right| * /|\mathrm{g}| & =2,5 \cdot 10^{-20} \mathrm{Kg} \cdot \mathrm{m} \cdot \mathrm{s}^{-2} / 9,81 \mathrm{~m} \cdot \mathrm{s}^{-2}= \\
& =2,55 \cdot 10^{-21} \mathrm{Kg} .
\end{aligned}
$$

To determine the number of water molecules having a weight $\mathrm{m}_{\mathrm{w}}$ :

$$
\begin{gathered}
\mathrm{m}_{\mathrm{w}} / 18 \mathrm{D}=2,55 \cdot 10^{-21} \mathrm{Kg} / 18 \cdot 1,67 \cdot 10^{-27} \mathrm{Kg}= \\
=84830,34,
\end{gathered}
$$

where: $18 \mathrm{D}\left(=18 \cdot 1,67 \cdot 10^{-27} \mathrm{Kg}\right)$ - the mass of one proton.

Thus, in the earth's conditions one proton "can raise" a drop consisting of 84830 molecules of water [2].

Compose another proportion:

high charge density.

Besides, boiling water can acquire a positive charge upon contact of the liquid with an open flame. This happens because the top part of the flame is always positively charged [3]. Moreover, the positive charges that appear in a flame, form an electric current, directed up $[2,3,8]$.

To be clear, can be considered generation and distribution of positive and negative charges in the flame of methane [6]:

$$
\mathrm{CH}_{4}+2 \mathrm{O}_{2} \rightarrow 2 \mathrm{H}_{2} \mathrm{O}+\mathrm{CO}_{2} \rightarrow \mathrm{H}_{2} \mathrm{O}+\mathrm{H}_{2} \mathrm{CO}_{3} \Rightarrow \mathrm{HCO}_{3}^{-}(\downarrow)+\mathrm{H}^{+}(\uparrow)(2)
$$

Thus, it is possible to offer two (at least) causes positive electrification of boiling water and rising steam, respectively.

Flying hot air balloon

Equation (2) describes the Lorentz force $F_{L}(1)$ has previously been used successfully for a satisfactory explanation of charge distribution in a gas burner of the balloon and the occurrence of the force that lifts the balloon. As follows from equation (2), only the positively charged particles move up the flame (particles with a negative charge moving downward). As can be seen from the design of the balloon (Figure 4), it will catch only particles with a positive charge.

Thus, the hot air balloon will acquire positive charge and move up under the action of the described Lorentz force $F_{L}$ (1) $[8]$.

For this reason, it was analyzed the possible impact of this force on the flight of a balloon, is provided with a gas burner. 
Thus, it was calculated that described the Lorentz force $F_{L}$ (1) 63.4 times more effective than the Archimedes force. In any case, it is right for the balance of the flying balloon in the air [8].

It is also necessary to say that the suggested reasons for this positive electrification of boiling water, and gas that appears in a gas burner have a convincing experimental confirmation $[9,10]$.

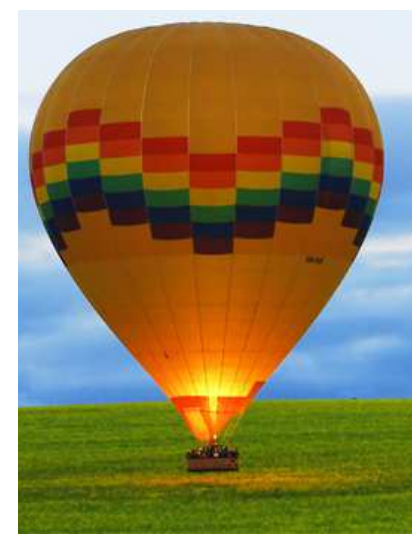

Figure 4. This is the start of hot-air balloon.

\section{The flying insects and birds}

It is believed that insects and birds can receive a positive charge during the flight, when their wings and body rub against the air. To verify the validity of such an opinion, such experiments were carried out.

Firstly, the electric potentials of water that was in contact with birds' or insect's feathers were determined. The electrical potentials of such water were measured relative to the same water prior to its contact with these objects. In fact, the electric potential of these waters, were measured as the potential flow or potential filtering [11]. All measurements have shown that after contact with the feathers of birds or insects, water acquires a positive potential of $+(100-200$ $\mathrm{mV})$. The amount of water used $(50-200 \mathrm{ml})$ varied depending on the size of these objects.

Secondly, the electrical potential of the water that contacted the feathers of birds or insects was also determined spectrally. To understand the essence of this method, it is necessary to take into account that the UV absorption of water depends on its electrical potential. As was shown earlier, the positive electrization of water is accompanied by the appearance of a maximum at $205-210 \mathrm{~nm}$ on its UV absorption spectra. On the contrary, the negative electrification of water leads to the appearance of a peak with a maximum at $\sim 195 \mathrm{~nm}$ on the same spectra. It should also be taken into account that uncharged water does not have a significant absorption of UV radiation in the range from 180 to $240 \mathrm{~nm}$ [12]. As a result, using this relationship, it was found that the contact of water with these feathers is always accompanied by the appearance of significant absorption at $205-210 \mathrm{~nm}$ on the UV spectra of water absorption. Thus, the fact that water contact with the established feathers leads to a positive electrization of water has been shown in two independent ways. From this it can be concluded that the feathers of birds and insects have a positive charge. The most probable cause of this positive electrification is their special sorption selectivity in relation to positive air ions. It is obvious that such sorption selectivity of bird and insect feathers is most effective when they come into contact with the air flow, i.e., by electrically contacting the feathers with a stream of air. It is natural to expect that the positive electrification of the bodies of insects and birds makes them susceptible to the action of the described Lorentz force $\mathbf{F}_{\mathbf{L}}$ (1). It is also natural to expect that such positive electrification, in combination with the action of the described force, increases the volatility of both insects and birds.

\section{Flying aircraft}

It is natural to assume that positive electrification can increase not only the lifting force of the described objects, but also the aircraft. This may correspond to reality, because the positive electrification of an airplane can occur as a result of two physical processes, at least.

First, the metal body of the aircraft can acquire a positive charge in accordance with rule of Kyon [6]. Since the dielectric permittivity of air is $\sim 1$ [7], and dielectric permittivity typical of metals accepted as $\infty$ [4], the metal body of an airplane must acquire a positive charge. Second, the metal body of an airplane will acquire a positive charge due to thermal emission of electrons [4]. This will definitely happen, since the main body of an airplane is very hot (Figure 5) [13]. Whatever it was, but the positive electrification of an airplane may occur [14].

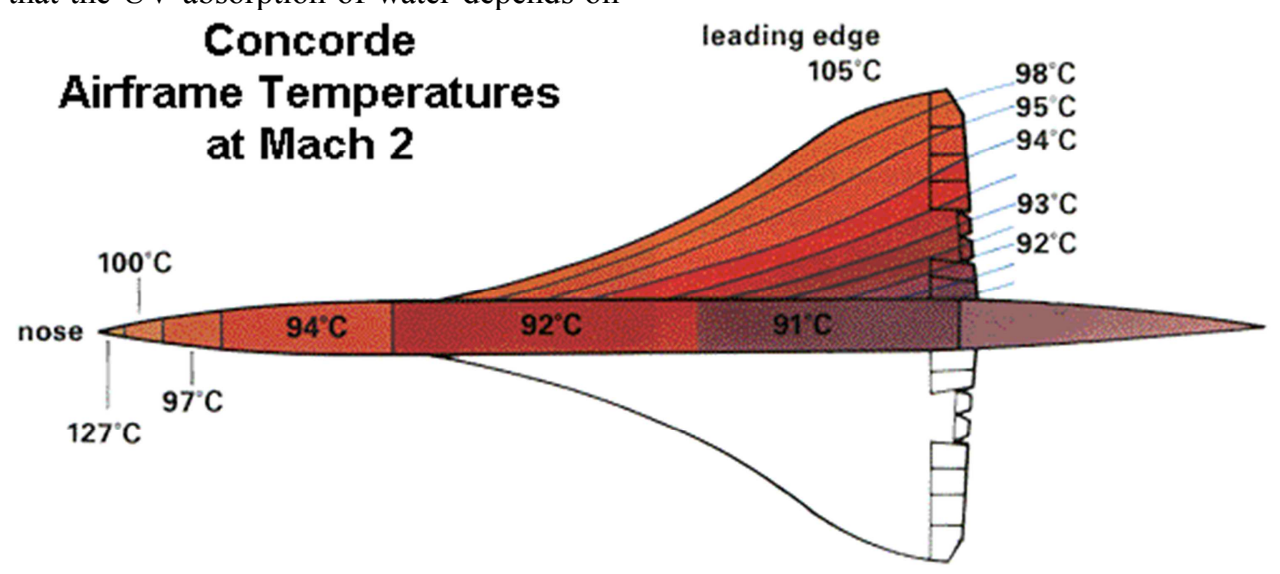

Figure 5. This is the heating of the body of the Concorde flying at a speed of $\sim 2450 \mathrm{~km}$ per hour (Mach 2) near the earth's surface (20 $\left.{ }^{\circ} \mathrm{C}, 1 \mathrm{~atm}\right)$. 
The up and down moved rackets

It was early shown that the positive charges generated in the flame form an upward current [2, 3, 8]. It was particularly shown that the up-directed acceleration of one proton is $4,175 \cdot 10^{7} \mathrm{~m} \cdot \mathrm{s}^{-2}$ [2]. For this reason, this proton can theoretically overcome a distance of $\sim 2,1 \cdot 10^{7} \mathrm{~m}$ $(\sim 21000 \mathrm{~km})$ in the first second after formation in the flame.

Therefore, the shell of the space rocket will be positively charged by positive charges of the rocket engine flame: it is clear that the electrification of the body of a space rocket can occur immediately after the launch of a rocket engine. Therefore, it is natural to expect that after such a positive electrification the shell of the space rocket will experience the action of the described Lorentz force $F_{L}(1)$. It is also natural to expect that all this will inevitably manifest itself in increasing the lift of the rocket engine.

In view of these considerations, it is not surprising that the described principle of the engine of UFO crashed in the German Alps in 1936, according to Henry Stevens [15]: "The engine of his... produced electrons and positrons. The positrons are attracted to the top of the sphere and created the levitation".

Moreover, the action of described Lorentz force $F_{L}(1)$ on the positively charged racket body blocks the movement of the rocket body in the horizontal direction. Pushes or pulls a rocket engine to a rocket, this is of fundamental importance for the balance of a rocket. Indeed, a stable equilibrium of the body of a space rocket is possible if the lifting force does not push the rocket from below, but pulls from above (as the described Lorentz force pulls up the positively charged missile body).

\section{Conclusion}

Due to the daily rotation of the Earth the lower layers of earth's atmosphere are continuously crossed by horizontal lines of the geomagnetic field. For this reason, near the earth's surface there is an upward-directed Lorentz force. This force can increase the lifting force of flying objects, which have a positive charge. The action of the upward directed Lorentz force blocks the deflection of the racket's body in the horizontal direction, that is, ensures its equilibrium.

\section{References}

[1] Feinman, R., Leiton, R., and Sands, M. (1965) FLP 5, Moscow: Mir. In Russian.

[2] Pivovarenko, Y. (2015) A Charge Distribution in the Earth's Atmosphere. American Journal of Physics and Applications. 3 (3), 67-68. doi: 10.11648/j.ajpa.20150303.11.

[3] Pivovarenko, Y. (2016) Diamagnetism Flame. Faraday Mystery. GJSFR. 16 (1), 53-55.

[4] Kuchling, H. (1980) Physik. Leipzig: VEB Fachbuchverlag. In German.

[5] Krasnogorskaja, N. V. (1984) Electromagnetic fields in the earth's atmosphere and their biological significance 1, Moscow: Nauka. In Russian.

[6] Nekrasov, B. V. (1974) General chemistry 1. Moscow: Chemistry. In Russian.

[7] Fernandez, D. P., Mulev, Y., and Goodvin, A. R. H. (1995) A database for the static dielectric constant of water and steam. J. Phys. Chem. Ref. Data. 24 (1), 33-69.

[8] Pivovarenko, Y. (2017) The Flight of the Balloon and the Daily Rotation of the Earth. World Journal of Applied Physics. 2 (2) 32-35. doi: 10.11648/j.wjap.20170202.12.

[9] Fialkov, A. B. (1997) Investigation on Ions in Flames. Prog. Energy Combust. Sci. 23, 399-528.

[10] Vincent-Randonnier A., and Teixeira D. (2008) Plasma assisted methane diffusion flame. International Journal of Plasma Environmental Science and Technology, 2 (2), 119127.

[11] Fridrichsberg D. A. (1974) Course of colloid chemistry. Leningrad: Chemistry. In Russian.

[12] Pivovarenko, Y. (2015) UV Absorbance of Aqueous DNA. European Journal of Biophysics. 3 (3) 19-22. doi: 10.11648/j.ejb.20150303.11.

[13] Bilimovich, B. F. (1981) Thermal phenomena in engineering. Moscow: Prosweschenije. In Russian.

[14] Vonnegut B., and Little A. D. (1965) Electrical behavior of an airplane in a thunderstorm. Technical report for Federal Aviation Agency. Massachusett: Cambridge Inc.

[15] Stevens H. (2003) Hitler's Flying Saucers: A Guide to German Flying Discs of the Second World War. Kempton, USA: Adventures Unlimited Press. 